\title{
Systematic Review of Literatures on Community-Based Health Insurance: Experiences from Developing Countries
}

\author{
Tariku Negasa Gida \\ Department of Accounting \& Finance, Wollega University, Nekemte, Ethiopia
}

\begin{abstract}
Access to healthcare services are an essential for maintaining and improving health of citizen. Good health is a key to sustained economic, social development and poverty reduction. Universal health coverage means that all people have equitable access to health services, improved quality of health services, and financial-risk protection. Community Based Health Insurance (CBHI) schemes are expected as a transitional mechanism to achieving universal coverage for health care in developing countries. CBHI schemes are characterized as hybrid arrangement from both traditional risk-sharing and formal health insurance policies. CBHI schemes are built upon the principles of social solidarity and common benefits to provide financial protection against medical expenses. To assess the ability of such schemes in meeting objectives of UHC, this study aims to systematically reviews of the existing theoretical literatures and empirical evidence on three outcomes; conceptual definition, characteristics of the scheme, and challenges to the success of the community based health insurance in developing counties. The study employed a qualitative research methodology by applying the basic principles of a systematic review in order to assess the existing literatures on the effectiveness and challenges of CBHI schemes in developing countries. This study totally relies on secondary sources which were collected from published works on journals, newspapers, published and unpublished articles of credible and reliable online sources. The review of literatures shows that the major challenges of the schemes are adverse selection, limited risk pool, poor financial risk protection, lack availability and quality of services, and lack of professional and standardized management. To overcome the challenges, all possible solutions were recommended.
\end{abstract}

Keywords: Community-based health insurance, Universal health coverage, Rural, Informal sector, Challenges, Effectiveness, Healthcare Financing

DOI: $10.7176 / \mathrm{JESD} / 11-21-03$

Publication date: November $30^{\text {th }} 2020$

\section{Introduction}

In developing countries, the governments are facing with the challenge of providing access to equitable healthcare for their citizens. African governments have tried to address the problem of access to healthcare through Government subsidies and cooperation with non-government actors such as NGO and the private sector.

Health care financing is one of the most challenging problems facing the world's poorest populations, especially in developing countries. Most of the population in low and middle income countries is neither covered by social security nor have access to health insurance. The health financing system in developing countries are characterized by a high reliance on external assistance and out-of-pocket payments (SIAPS, 2016). Out-of-pocket payment is the major option to pay for medical care and in case of severe sickness, when specialized treatment at a higher level is required, many households face difficulties to cover the cost of inpatient care and treatment costs. For many households, it is difficult to find money for seeking health care even for common illnesses in certain periods of the year (Yared, 2009).

Community-Based Health Insurance (CBHI) schemes are an emerging tool for offering financial protection against the cost of illness or medical bills and improving access to quality health services for low-income rural households who are excluded from formal insurance (Donfouet \& Mahieu, 2012). It is a scheme that requires community members to prepay for health services. In CBHI schemes, community members pool their resources together to share the financial risks of health care, own the scheme and control its management, including the premiums collection, make the payment to healthcare providers, and the negotiation on the packages the schemes. It is a scheme that are based on voluntary and collective pooling of health risks and the ownership of schemes is heightened through community participation in scheme design (including setting premiums and benefits) and management (Purohit, 2014).

$\mathrm{CBHI}$ is scheme that share the aims to searching means for communities to satisfy their healthcare financing needs through pooled revenue and resource allocation decisions made by the community themselves. It is a form of insurance that allows members to pay small premiums on a regular basis to offset the risk of needing to pay large health care fees upon falling sick. However, unlike many insurance schemes, CBHI schemes are typically based on the concepts of mutual aid and social solidarity (Bennett; et al, 2004).

However, the scheme is much debated as a means of tackling the challenges of providing health care for the poor in developing countries without worsening their economic situation. Advocators of CBHI schemes argue that the scheme can be effective for reaching a large number of poor people who would otherwise have no financial 
protection against the cost of illness, especially in countries where national insurance schemes do not exist and/or where public health care funding is insufficient (Collins, et al., 2016). Additionally, CBHIs have the potential to solve many of the problems associated with insuring the informal and poor section of the population. They reduce adverse selection by grouping people together with varying levels of risk and insuring them as a group. And also it has demonstrated promising results for poverty reduction since it reducing the problems related to out-of-pocket payments (Gebremeskel, 2014). On the other side, opponents of the schemes argue that the risk pool is often too small, adverse selection problems arise, the schemes are heavily dependent on subsidies, financial and managerial difficulties arise, and the overall sustainability is not assured (Collins, et al., 2016). For the above arguments we can conclude that there is a debate on the concept of CBHI schemes.

Furthermore; in developing countries, launching and sustaining the CBHI schemes are not without ups and downs. Many studies show that the schemes are facing different problems; these are unwillingness membership, lack of awareness about insurance, adverse selection, non-renewal of membership, dissatisfaction on services provided (EHIA, 2015; Gebremeskel, 2014). Therefore, this study aims to systematically review the existing theoretical literatures and empirical evidence literatures on community-based health insurance experiences in the developing countries.

\section{Methodology}

This study was qualitative research, by its nature. It employed a qualitative research methodology by applying the basic principles of a systematic review in order to assess the existing literatures. To provide a synthesis of the existing knowledge on community-based health insurance schemes, this study relies on secondary sources which were collected from published works on journals, newspapers, published and unpublished articles of credible and reliable online sources of organizations deals with the community-based health insurance schemes, health care financing, and universal health coverage. Before starting a review, all the retrieved data were subjected to content analysis. Content analysis is a research tool used to determine the presence of certain words or concepts within qualitative data or texts or sets of texts and it has become a popular method for qualitative researches.

\section{Definitions, Concepts and Characteristics of CBHI Schemes}

Community-based health insurance is a generic term used to explain variety of resource mobilization strategy designed for access to health care financing through a greater involvement of the community in its designing and management. The schemes are named differently in different countries/programmes; such as mutual health organizations, community-based health financing, and community-based health insurance which are dominantly used and in this study also. There is no universally accepted definition of CBHI. Its definition varies from country to country and from the scheme to scheme. Thus, in this section we review different definitions of CBHI and conceptualize them.

$>$ Community-Based Health Insurance $(\mathrm{CBHI})$ is defined as a risk-pooling mechanism that tries to spread medical expenses across households with different health profiles to prevent catastrophic expenditures that come from unpredicted health events or chronic diseases, and enables cross-subsidies from rich to poor populations (EHIA, 2015). From this definition, in Ethiopia, we can conclude that CBHI schemes are subsidized by the government, that is by either federal, regional and/or local government.

$>$ Community-based health insurance is also defined as the scheme designed as a means for informal sectors to contribute some amount of money that is owned, designed, and managed by their members, and the schemes are a not-for profit type of health insurance that has been used by poor people to protect themselves against the high costs of seeking medical care and treatment for illness. It is mainly financed by the contributions/ premium regularly collected from its members (Adane, et al., 2014).

$>$ CBHI schemes are a community based organization that pools risk to cover health care expenditures. Such schemes are well positioned to monitor behavior and enforce contracts while at the same time reaching rural and informal sectors those over looked by many formal insurance policies. (Gebremeskel, 2014).

$>$ Community-based health insurance is defined as a pledge agreement requiring the health insurer to cover basic medical expenses in exchange of premium payments into a collective trust which is designed, owned, and administered by members (Uzochukwu, et al., 2015).

$>$ Community-based health insurance schemes are one way of mobilizing community resources to share in the financing of local health services. They represent promising mechanisms for increasing rural populations' access to health care and for generating additional financial sources for health. Additionally, they may be seen as a stepping stone to universal coverage (Fonta, 2010).

According to Shemeles (2012), community-based health insurance schemes have the potential to create awareness regarding the importance of insurance and minimizing the equity gap by; providing financial protection for informal segments of the population, reducing the problems related to out-of-pocket payments, building selfbelief among participants through community control mechanisms, and enhancing utilization of the health care scheme. 
Bennett, et al (2004) explained that CBHI can help to improve financial access, utilization, resource mobilization, and quality of health care services through cooperative, community efforts. The most obvious effect of CBHI schemes is to reduce how much people pay for health care when they seek care. Fixed and prepayment of premium to $\mathrm{CBHI}$ scheme lead to more frequent utilization of health care services and less delay in seeking care. Furthermore, members of $\mathrm{CBHI}$ schemes are unlikely to need to borrow and go into debt in order to cover health care costs.

Purohit (2014) states two basic underlying assumptions of CBHI to function. The first assumption is based on providing insurance coverage to people in the rural, informal sector and the poor because they have very limited protection from other sources and mostly rely on government services that do not protect them against catastrophic illnesses. The second assumption being that healthcare financing seem particularly relevant to low-income countries where government revenue is limited and there is currently extensive reliance upon out-of-pocket payment. Therefore, CBHI can be seen as one of the potential ways to extending the health insurance to the rural and low income population.

CBHI schemes are characterized as hybrid arrangement from both traditional risk-sharing and formal health insurance policies. Similar to traditional risk sharing systems (like Edir in Ethiopia), CBHI schemes are built upon the principles of social solidarity and common benefits to provide financial protection against medical expenses, whereas payment of premiums also makes them similar. In contrast, CBHI schemes differs from formal insurance contracts is that CBHIs are non-profit organizations, and therefore the premium is based on the average risk profile of the community as a whole, whereas formal insurance aims at profit maximization and premiums are fixed above the expected risk level of individuals. Unlike formal insurance contracts, members of CBHI are expected to participate in administration and supervision activities the schemes. (Jacobs et al 2008).

CBHI schemes appear appropriate for providing insurance coverage to persons with limited protection from other sources, such as those who are not engaged in formal sector employment. They also seem particularly relevant to low-income countries where government revenue is limited and there is currently extensive reliance upon out-of-pocket payment (Bennett, et al, 2004).

Generally, CBHI schemes are characterized by the following institutional design features:

(i). Dynamic risk pooling, where the scheme is a prepayment mechanism with pooling of health risks and of funds taking place at the level of the community or a group of people who share common characteristics (such as geographical, occupational ethnic, religious, gender, etc);

(ii). Membership premiums are often a flat rate (community-rating) and are independent of individual health risks. There is a solidarity in the scheme; i.e. risk sharing is as inclusive as possible within a given community;

(iii).Participatory decision making and management;

(iv). Voluntary affiliation;

(v). Non-profit character; i.e. it operates on a non-profit basis (WHO, 2019).

In CBHI, there is a participatory decision-making and management structures, which is said to improve the transparency and accountability of the scheme. It also has the potential to enhance community empowerment and allow the voicing of community members' concerns and expectations in the management of local health systems. It can also build trust and encourage familiarity with the concept of insurance (WHO, 2010).

In generally, when CBHI schemes are fragmented, voluntary and with/without subsidization for vulnerable population groups, are limited in supporting progress towards universal health coverage. Such CBHI schemes provide only moderate financial protection and access to needed health care for those enrolled. Moreover, those who cannot afford to pay the premiums do not get enrolled, which excludes the poorest and most vulnerable people. CBHIs tend not to be able to cover a large share of those working in the informal sector, which is usually the biggest part of the population. In addition, CBHIs are usually small, separate pools with little capacity for redistributing risks. The rationale of pooling at a level close to the community is contradictory to the principle of accumulating funds and sharing risks in a large pool (WHO, 2019).

\section{Types of Community Based Health Insurance Schemes}

As discussed earlier, there are different variety of resource mobilization strategy designed for access to healthcare financing through a greater involvement of the community, there are different types of CBHI schemes on the basis of their design, community involvement in setting-up, resources mobilization, management and supervision the scheme.

The most common forms of the schemes are: (i) Community prepayment health organizations, (ii) Provider based health insurance, and (iii) Government-run but community-involved health insurance (Anagaw, 2015).

\subsection{Community prepayment health organizations}

Community prepayment health organizations are characterized by voluntary membership and payments are made in advance in order to cover potential medical expenses. Members of the schemes pay premiums on a regular basis, 
usually when their incomes are high. Such schemes are often initiated with the technical and financial support of NGOs and thereafter the community takes full responsibility for administering and managing the scheme. Local governments may also play a role in encouraging and supporting the efforts of such schemes. The community participates in designing the scheme and decides on the level of benefit and the corresponding premium. In addition, members participate actively in administration and supervision (Arhin-Tenkorang, 2001).

\subsection{Provider based health insurance schemes}

These types of health insurance schemes are initiated by healthcare providers (such as a town or regional hospitals) to encourage utilization of healthcare services. The schemes mainly cover expensive inpatient care and hospitals and may have recourse to external funds to subsidize service costs. In this scheme, the health care providers are responsible for mobilizing resources and providing health care services. The role of the community in designing and administering the scheme is limited (Anagaw, 2015).

\subsection{Government run community-involved health insurance}

Government run and community-involved health insurance schemes are often linked to formal social insurance programmes with the objective of creating access to a universal health care system (Jakab \& Krishnan, 2001). Unlike other models, government initiated schemes often cover both basic curative and inpatient care. The government (central or regional) plays a substantial role in initiating, designing and implementation of such schemes. The participation of the community in such schemes varies substantially across countries (ArhinTenkorang, 2001).

Finally; based on his review, Anagaw (2015) concluded that, there is a link between the scheme type and outcomes. He concluded that government-run community-involved insurance schemes appears less effective interms of reaching very poor people as compared to community prepayment insurance schemes. However, government-run community-involved scheme are more effective in providing financial protection for beneficiaries, although it ignores marginalized groups or very poor people.

\section{Theories of CBHI Schemes}

In this section we review the two major theories (most cited) used to explain the theoretical framework of CBHI. These are Social Capital theory and Social Mobilization theory.

Social capital theory: Social capital is the term used to explain a positive product of human interaction. Social capital is a set of shared values that permits individuals to work together in a group to effectively achieve a common goal. Thus, social capital can be defined as the existence of a certain set of formal or informal networks, values or norms shared among the members of a group that permit cooperation and coordination among them (Fukuyama, 1995). Social capital theory states that social capital consists of characteristics of social organization such as formal and informal networks, norms, and social trust that assist coordination and cooperation for mutual benefit (Putnam, 1993). According to Woolcock and Narayan, (2000), the basic idea of social capital is that a person's family, friends, and associates constitute an important asset, that one can be called on in a crisis, enjoyed for its own sake, and leveraged for material gain.

Social capital can be conceptualized on the different dimensions which have the potential for both positive and negative impacts on development of the specific community and the country to the large. Such dimensions are: (i) community links such as extended families, local organizations, clubs, associations and civic groups in small communities to helping each other; (ii) network links between similar communities [horizontal] and between different communities [vertical]; (iii) institutional links through the political, legal and cultural environments of communities; and (iv) societal links between governments and their citizens through complementarity and embeddedness (Preker, et al.; 2012).

Empirical studies suggest that higher levels of social capital are positively correlated with improved development outcomes in areas such as agriculture, water and sanitation and microcredit in low-income countries (Brown \& Ashman, 1996; Woolcock \& Narayan, 2000).

According to Woolcock and Narayan (2000), social capital helps the poor to share the risk and vulnerability. Thus, CBHI which aims at risk sharing and vulnerability may be well accepted by a community that possesses a high stock of social capital. A larger level of social capital is associated with a high level of altruism among individuals; this makes it possible to take into consideration the well-being of other members of the group.

The presence of social capital always has a positive effect on a community's welfare. According to Sobel (2002), social capital is explained as circumstances in which individuals can benefit from group membership. Thus, social capital refers to social life networks, norms, and trust that enable households to act together more effectively to pursue shared objectives.

This social capital in the community can be an asset for the development of CBHI, thus contributing to the demand for CBHI at the community level. Due to the nature of CBHI schemes, their success highly depends on the existence and survival of social capital in the community. CBHI can therefore attain sustainability, 
effectiveness and be long-lasting with the help of social capital in a community; because social capital has a positive influence on the community demand for insurance (Donfouet \& Mahieu, 2012).

Social capital is a prerequisite to implement CBHI. Due to the fact that social capital varies among countries, regions and even among localities, the design and action programmes are very specific to the local level. This makes condition makes it difficult to replicate the schemes in other areas (WHO, 2003).

Social Mobility Theory: The concept of social mobilization is defined as the process of bringing together all stakeholders and individual influences to increase awareness of and demand for health care, assist in the delivery of resources and services, and promote sustainable individual and community involvement (WHO. 2020). In other word, social mobilization can also be defined as the use of planned actions and processes to reach, influence, and involve all stakeholders across all relevant/concerned bodies, including the national and community level to raise awareness, change behavior, change policy, demand a specific development programme, or reallocate resources or services'. Social mobilization theory is a theory recognized as effective instrument for health care promotion specially when people are reluctant to respond positively to health programme.

Social mobilization is a multi-level, dynamic approach that can be initiated either top-down or bottom-up. Community is perceived in its broadest sense to include all those who have a role and responsibility in effecting change. As information is made available and understandable to both experts and lay people, broad ownership and popular support are created (Russell and Levitt-Dayal, 2003). Hence, due to the inability of governments to reach rural people and the informal sector, communities have highly been mobilizing themselves to secure financial protection against the cost of illness (Preker, et al. 2012).

The social mobilization approach can be used in different health care programs including family planning, community based health insurance, and so on. A community based health insurance like any other health program, to be effective, needs a multipronged approach and broaden public support through social mobilization. In case of $\mathrm{CBHI}$, given the fact that most of people are unaware about benefits of health insurance, community need to be mobilized in order to understand and to adhere to the programme. It should also be noted that the CBHI to be sustainable needs mobilization for human and financial resources.

According to McKee (1992), there are five approaches to mobilizing human and financial resources: (i) political mobilization, (ii) government mobilization, (iii) community mobilization, (iv) corporate mobilization, and (v) beneficiary mobilization. Social mobilization uses community events to attract the attention of policy makers, community members, and media representatives and motivate them to take action on a specific issue such as immunization, literacy, or family planning. Social mobilization amplifies advocacy activities, strengthens communication, and allows many more societal partners to participate in the program. To be successful a CBHI program needs to use all those approaches to mobilize human and financial resources.

\section{Development Framework of CBHI}

The aim of Universal Health Coverage (UHC) is to strengthen health system of world population beginning from primary health care. It involves equity in access to health services, good enough of quality of health services, and financial-risk protection. World Health Organization has stated that "UHC is the single most powerful concept that public health has to offer." (WHO, 2010). Thus, UHC is a social aspiration of most nations and is currently a top health policy priority for the developing countries. However, there is no 'one size fits all' strategy for implementing UHC in developing countries. Some countries such as Republic of Korea, Colombia, and Mexico used top-down approach public financing (tax-based) and Social Health Insurance (SHI), without starting of CBHI, whereas some countries (especially developing countries) uses bottom-up approach i.e. community based health financing (EHIA, 2015).

Furthermore, upper-middle-income nations such as Colombia, Costa Rica, and Thailand have already claimed success of UHC goal; whereas the low and middle income countries as diverse as Senegal, Ethiopia, Ghana, Peru and Vietnam are striving to expand health insurance coverage (using both/either of CBHI and/or SHI) for their populations (Bitran, 2014).

On the other hand; related to the link between scheme design characteristics and effectiveness, Aragaw (2015) conclude that top-down government-run schemes are better in ensuring healthcare access and reducing out-ofpocket expenditure as compared to community-run schemes. As well, the schemes that have access to external sources of finance (in addition to premium) are more effective in providing financial protection and expanding access to healthcare services, even though it rarely reaching the marginalized groups.

To this end, Wang and Pielemeier (2012) suggested that a bottom-up approach as more suitable model to accelerate progress toward UHC for developing countries. They provided a three-model framework for the development of CBHI schemes in low-income countries. The three models are; generic model, enhanced model, and nationwide model. The characteristic of these models are presented in Figure 1 below: 
Figure 1: CBHI Development Framework

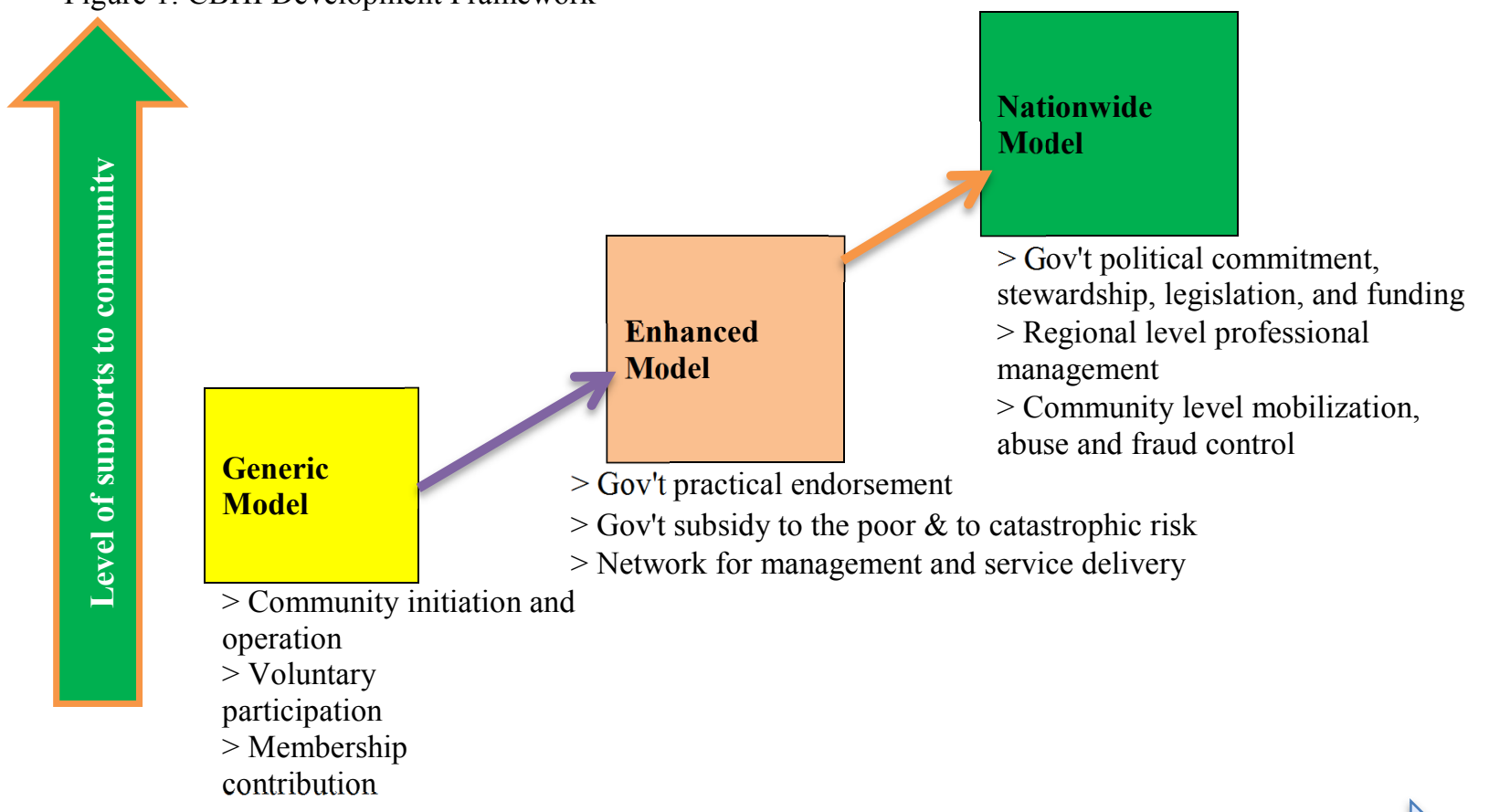

Tax-based / Social Insurance characteristics

Source: Adapted from Wang and Pielemeier, 2012

\title{
7. Challenges of Community-Based Health Insurance
}

The operation of CBHI schemes are not free from problems/challenges that limits scheme from achieve its primary objective. The major challenges are review as follows:

\begin{abstract}
Adverse Selection
In CBHI adverse selection occurs when high-risk or sick individuals or households are more likely to become a member of the scheme than the low-risk or healthy individuals. Empirical studies show that individuals with better health were less likely to enroll in CBHI schemes (Ahmed, et al 2018; and Purohit, 2014). Voluntary membership to the scheme is the risk factor of adverse selection that may challenge financial sustainability of the scheme.

To enhance sustainability of CBHI schemes, it is important to balance strategies promoting enrollment and access, with strategies that would help minimize adverse selection problem in the CBHI schemes; as an example, (i) mandatory enrollment of all individuals/ households in the catchment area/district of the scheme; since it decreases adverse selection by lowering probability of having only sick individuals enrolled in the scheme; (ii) setting different premiums for individuals having different risk levels ; (iii) extending the waiting period for accessing healthcare after enrolled into the scheme; (iv) enrolling low-risk people only (Fadlallah et al. 2018).
\end{abstract}

\section{Limited Risk Pool}

CBHI schemes have failed to address the very low enrollment rates and lack of risk pooling for the people in unorganized sector. Because it is still constrained by limited membership contributions from low-income informal sector members (Bhat \& Jain, 2006). According to the study conducted in China, there is a low demand despite great need for people to join such schemes. This is because CBHIs has a feature of voluntary contribution from its members. However, there are many poor people who cannot even afford minimum premium for the schemes and as a result their needs are not converted into demands (Liu and Hsiao, 2003). The study conducted by Macha et al. (2014) also reveals that lack of understanding of the risk pooling principle was a factor limiting enrolment and explaining drop out and finally leads the scheme to the question to continue or not.

Even though initial uptake is high, high dropout rates highly impend the sustainability of CBHI schemes. As existing literatures shows that there is high rate of non-renewal membership I.D card due to different reasons. The factors that are most likely to influence renewal rates of membership are health status of the households, quality of service offered, affordability of premium, lack of understanding about the scheme and insufficient information on how to use the insurance policy are the key challenges for success of the scheme. 
To address this problem, greater awareness creation campaign to the community and understanding about the insurance concept is required. Existing literatures also indicates that informal sector of urban residents are ignored from equitable access for health service, however, it enables the government to attain UHC goal and enable the scheme for sharing the risk on large number of people.

\section{Limited Financial Risk Protection}

CBHI schemes are expected to provide financial risk protection by reduce out-of-pocket spending of their members, while increasing their utilization of health care services (Jakab \& Krishnan, 2001). However, due to low risk pooling and revenue collection from their members in the form of premiums are very low and low subsidies from the government leads to limits financial risk protection for their members. CBHIs have really challenged in extending coverage to the needy and eligible people and limited to broaden health service coverages, because there is low risk pool and the schemes are failed to increase peoples' interest to capture large number of people which leads to low enrollment rates.

The effectiveness of financial risk protection offered by an individual CBHI scheme can be measured by extent to which the benefit package offered covers a comprehensive package of services, particularly higher cost services. If high cost services (commonly used) are excluded from the benefit package, then effective financial risk protection may be limited or under the question. However, WHO suggested that the CBHI schemes are not be expected to provide a greater source of financing or coverage, hence policy option for financial protection arrangements such as compulsory membership and the subsidies by government for those unable to pay have shown more potential to reach UHC goals than voluntary membership.

\section{Lack of Quality Service and Availability}

Quality and availability of health service is one of the main supply side factors identified to limit enrolment to the scheme. The quality of healthcare services can be measured in different dimensions; such as availability of drugs, diagnostic equipment, referral system, waiting time, staff motivation \& availability, and so on. Low quality of healthcare services at public facilities was one of the main factors discouraging people from joining the scheme and limits renewal of membership. When drugs are out-of-the-stock, the scheme members have to buy drugs at private pharmacies at high cost (Macha et al.; 2014). Availability of health care (particularly hospital care) is also an issue; in some schemes are too remote from any hospital, or desired services are simply not offered at the local health post/centers. In such cases, the schemes may contract with regional-level hospitals and include transportation costs to those hospitals in their benefits packages (Bennett et al, 2004). Uncertainty related to the availability of medical supplies and limited working hours at the dispensary also creates non-renewal membership I.D. card which affects effectiveness and sustainability of the scheme (Macha et al.; 2014).

Furthermore, another quality related problem in the schemes is maltreatment by health care providers/workers, that is unfair treatment between card user (members of the scheme) and cash payers (non-members). This is due to the fact that non-member patients immediately pay their medical costs in-cash (i.e. what the health service provider needs, may be by considering time value of money), whereas members of the schemes use membership I.D. card only to get services from the providers. Therefore, this maltreatment creates members' dissatisfaction which leads to non-renewal their I.D. cards and also discourages prospective members to become a member and which negatively affects sustainability of the scheme.

\section{Lack of professional and committed management}

On the other hand, lack of skilled manpower and their low concerns and commitments from the stakeholders (such as; community, management and service providers) are management related challenges that affects the schemes effectiveness and sustainability (Gutama, 2019). This is might be due to poor incentives for the management of the schemes and service providers, which should be considered. Such management related challenges are responsible for the creation of the such problems as; low awareness creation, boring claims procedures, and longtime taking for claim settlement. Thus, to increase the schemes sustainability, increasing number of members and retain the existing members the claims procedures of the schemes should be simplified and time lag between hospital discharge to reimbursements of medical expenses to the beneficiaries should be highly reduced. (Purohit, 2014).

Poor communication and information flow between people who are managing the schemes and the beneficiaries limits the schemes' utilization and effectiveness. Better and clear communication has been described as a sufficient condition for poor members to enjoy greater share of scheme benefit (Ranson, et al., 2007).

\section{Conclusion}

Following the United Nations political declaration on universal health coverage; the most comprehensive set of health commitments ever adopted, many governments of low-and-middle income countries have been trying to provide basic health services for their population. As a result of the declaration, find additional sources of revenue 
to finance healthcare which are all inclusive, sustainable, and suitable to the socio-economic situations of individuals in the formal sector, rural people and workers of informal sectors of the urban population become mandatory. Hence, CBHI schemes are considered as one of the options mentioned to improve financial access, utilization, resource mobilization, and quality of health care services through cooperative, community efforts.

This study aims to systematically reviews of the existing theoretical literatures and empirical evidence on the community based health insurance experience in the developing counties. The review literatures we conclude that the community-based health insurance schemes have the potential to reaching a large number of low-income populations by creating awareness regarding the importance of insurance and minimizing the equity gap by; providing financial protection for informal segments of the population, reducing the problems related to out-ofpocket payments, building self-belief among participants through community control mechanisms, and enhancing utilization of the health care scheme. This is due to the fact that fixed and prepayment of premium to CBHI scheme lead to more frequent utilization of health care services and less delay in seeking care and members of the schemes are unlikely to need to borrow and go into debt in order to cover health care costs. However, the poor and workers in informal sectors in urban excluded groups from the schemes and needs governments due considerations. At the same time, there is large variation in the share of CBHI schemes in the total resources of local health systems which needs a continues and rigorous evaluation of the resource generation capacity of the schemes.

The review also shows that the schemes that have access to external/additional sources of finance are more effective in providing financial protection and expanding access to healthcare services but not at reaching out to the marginalized groups. This suggests that subsidies are more likely to increase financial protection and expanding access to healthcare by the scheme. Regardless of scheme type is that schemes where the community plays a role in scheme design and implementation are better at ensuring access to health care and financial protection.

The study also shows that the operation of CBHI schemes are not without ups and downs that limits scheme from achieve its primary objective. The review of literatures shows that the major challenges of the schemes. For instance; (i) adverse selection due to voluntary membership to the scheme, (ii) limited risk pool which creates from lack of understanding of the risk pooling principle was a factor limiting enrolment and explaining drop out, (iii) poor financial risk protection due to low risk pooling and revenue collection from their members in the form of premiums are very low and low subsidies from the government, (iv) lack of quality service that discouraging people to joining the scheme and limits them from renewal of membership, and (v) lack of professional and standardized management that comes from lack of skilled manpower and low concerns and commitments from the stakeholders.

\section{References}

Acharya, A. S., Vellakkal, F., Taylor, E., Masset, A., Satija, M., Burke, \& S. Ebrahim, S. (2013). The impact of health insurance schemes for the informal sector in Low- and Middle-Income countries: A Systematic Review. Policy Research Working Paper 6324, World Bank.

Adane, K., Measho, G., \& Mezgebu Y. (2014). Willingness to pay for community based health insurance among households in the rural community of Fogera district, North West Ethiopia. Journal of Economics, Finance and Management Sciences, 2(4), 263-269. doi:10.11648/ j.ijefm.20140204.15

Ahmed, S., Sarker, A. R., Sultana, M., Chakrovorty, S., Hasan, Z., Mirelman, A. J., \& Khan, J. A. M. (2018). Adverse Selection in Community Based Health Insurance among Informal Workers in Bangladesh: An EQ5D Assessment. International Journal Environmental Research and Public Health. doi:10.3390/ijerph 15020242

Ahuja, R. \& Jütting, J. (2004). Are the poor too poor to demand health insurance? Journal of Microfinance/ESR Review, 6(1): 1-20.

Anagaw, D. M. (2015). Essays on evaluating a community based health insurance scheme in rural Ethiopia. Thesis to obtain the degree of Doctor from the Erasmus University Rotterdam, Netherlands.

Arhin-Tenkorang, D. (2001). Health insurance for the informal sector in Africa: design features, risk protection, and resource mobilization. WHO/Commission on Macroeconomics and Health. Working Paper No. WG3:1. World Bank, Geneva.

Bennett, S., Kelley, A.G., Silvers, B., Gadhia, R., \& Salamata, L. (2004). 21 questions on CBHF: An overview of community-based health financing. Partners for Health Reform plus, Bethesda, Maryland, USA.

Bhat, R. \& Jain, N. (2006). Factors affecting the demand for health insurance in a micro insurance scheme. Working Paper №: 07-02, India Institute of Management, Ahmadabad.

Centre for Development and Population Activities (CEDPA) (2000). Social mobilization for reproductive health: A trainer's manual. Washington, DC.

Cochran, W. G. (1963). Sampling techniques ( $2^{\text {nd }}$ Ed.). New York, John Wiley and Sons, Inc.

Collins, D., Kalisa, I., Musange, S., Saya, U., \& Kunda. T. (2016): The development of community-based health insurance in Rwanda: Experiences and Lessons: Technical Brief

Doetinchem, O., Carrin, G., \& Evans, D. (2010). Thinking of introducing social health insurance? World Health 
Report. Background Paper, No 26

Donfouet, H.P., \& Mahieu, P. (2012). Community-based health insurance and social capital: a review. Health Econ Rev 2(5). Available at: https://doi.org/10.1186/2191-1991-2-5

Ethiopian Health Insurance Agency. (2015). Evaluation of community-based health insurance pilot schemes in Ethiopia: Final report. Addis Ababa, Ethiopia.

Fonta, W. M., Ichoku H. E \& Ataguba, J. E. (2010). Paying for community-based health insurance schemes in rural Nigeria: The use of in-kind payments. African review of money finance and banking

Fukuyama, F. (1995). Trust: The social virtues and the creation of prosperity. New York: Free Press.

Gutama, N. (2019). Assessing the practices and challenges of community based health insurance in Ethiopia: The case of Oromia national regional state district of Gimbichu. International Journal of Advanced Research, 7(5), 734-754. DOI URL: http://dx.doi.org/10.21474/ IJAR01/9095

Hong, W., \& Pielemeier, N. (2012). Community-based health insurance: An evolutionary approach to achieving universal coverage in low-income countries. Journal of Life Sciences 6: 320-329.

Jacobs, B., M. Bigdeli, M. Pelt, P. Ir, C. Salze and B. Criel (2008). Bridging community-based health insurance and social protection for health care: A step in the direction of universal coverage? Tropical Medicine and International Health, 13(2), 140-143.

Jakab, M. \& Krishnan, C. (2013). Community involvement in health care financing: Impact, strengths and weaknesses. A Synthesis of the Literature.

Liu, Y. \& Hsiao, W.C. (2003). For the people, by the people: Community financing of healthcare in developing countries. Harvard Health Policy Review, 4, 102-111.

Macha, J., Kuwawenaruwa, A., Makawia, S., Mtei, G. \& Borghi, J. (2014). Determinants of community health fund membership in Tanzania: a mixed methods analysis. BMC Health Services Research. Retrived from: http://www.biomedcentral. com/1472-6963/14/538

McKee, N. (1992). Social mobilization and social marketing in developing countries: Lessons for communicators. Penang: Southbound.

Preker, A. S., Carrin, G., Dror, D., Jakab, M., Hsiao, W., Arhin-Tenkorang, D. (2002). Effectiveness of community health financing in meeting the cost of illness. Bull World Health Organ; 80(2):143-50. PMID: 11953793; PMCID: PMC2567719.

Purohit, B. (2014) Community based health insurance in India: Prospects and Challenges. Health, 6,1237-1245. http://dx.doi.org/10.4236/health.2014.611152

Putnam, R. (1993). Making democracy work: Civic traditions in modern Italy. Princeton, NJ: Princeton University Press.

Putnam, R. (2000). Bowling Alone: The Collapse and Revival of American Community. New York: Simon and Schuster.

Ranson, M. K. (2002). Reduction of catastrophic health care expenditures by a community-based health insurance scheme in Gujarat, India: Current experiences and challenges. Bulletin of the World Health Organization, 80, 613-621.

Ranson, M. K., Sinha, T., Chatterjee, M., Gandhi, F., Jayswal, R., Patel, F., Morris, S. S., \& Mills, A. J. (2007). Equitable utilization of indian community based health insurance scheme among its rural membership: Cluster randomized controlled trial. British Medical Journal, 334, 1282-12783. http://dx.doi.org/10.1136/bmj.39192.719583.AE

Russell, N. \& Levitt-Dayal, M. (2003). Igniting change: Accelerating collective action for reproductive health and safe motherhood. A Joint Thematic Paper of the ENABLE Project and The Maternal and Neonatal Health Program.

Shemeles A. (2012). Community based health insurance scheme in Africa, the case of Rwanda, Africa Development Bank. Working paper, 2012 (120): 13-7.

Solomon, F., Workie, M., Hailu, Z., \& Ashagari, T. D. (2015). Ethiopia's community-based health insurance: A step on the road to universal health coverage.

Systems for Improved Access to Pharmaceuticals and Services, (2016). Ethiopian national health insurance scaleup assessment on medicines financing, use, and benefit management: findings, implications, and recommendations. Submitted to the United States Agency for International Development by the Systems for Improved Access to Pharmaceuticals and Services (SIAPS) Program. Arlington, VA: Management Sciences for Health.

Uzochukwu, B. S., Ughasoro, M. D., Etiaba, E., Okwuosa, C., Envuladu, E., Onwujekwe, O. E. (2015). Health care financing in Nigeria: implications for achieving universal health coverage. Niger $\mathrm{J}$ Clin Pract. 2015;18(4):437-444.

Woolcock, M, \& Narayan, D. (2000). Social capital: Implications for development theory, research, and policy. World Bank, Research Observer 225-249.

World Health Organization (2003). Social health insurance. Report of a regional expert group meeting. regional 
office for South-East Asia, New Delhi, India

World Health Organization (2019). Characteristics of community-based health insurance. Retrieved on December 15, 2019, from: https://www.who.int/health_financing/topics/ community-based-healthinsurance/ keycharacteristics/en/

World Health Organization (2020). Community-based health insurance. Retrieved on October 28, 2020; from: https://www.who.int/news-room/fact-sheets/detail/community-based-health-insurance-2020. 